\title{
Ecological Vulnerability of Coral Reef Ecosystem in Wakatobi National Park During Indian Ocean Dipole Event
}

\author{
Hawis H. Madduppa ${ }^{1,3}{ }^{*}$, Alan F. Koropitan ${ }^{1}$, Ario Damar $^{2,3}$, Beginer Subhan ${ }^{1}$, MuhammadTaufik $^{4}$, La Ode Alam Minsaris ${ }^{2}$, \\ AM Azbas Taurusman ${ }^{3,5}$, Agus Ramli ${ }^{3}$, Arif Budi Purwanto ${ }^{3 \dagger}$ \\ ${ }^{1}$ Department of Marine Science and Technology, Faculty of Fisheries and Marine Science, Bogor Agricultural University (IPB \\ University), Bogor, Indonesia \\ ${ }^{2}$ Department of Aquatic Resources Management, Faculty of Fisheries and Marine Science, Bogor Agricultural University (IPB \\ University), Bogor, Indonesia \\ ${ }^{3}$ Center for Coastal and Marine Resources Studies, Bogor Agricultural University (IPB University), Bogor, Indonesia \\ ${ }^{4}$ Thematic Mapping and Integration Center, Geospatial Information Agency, Bogor, Indonesia \\ ${ }^{5}$ Department Fisheries Resources Utilization, Faculty of Fisheries and Marine Science, Bogor Agricultural University (IPB University), \\ Bogor, Indonesia
}

ARTICLE INFO

Article history:

Received October 13, 2017

Received in revised form September 10, 2019

Accepted September 12, 2019

\section{KEYWORDS:}

Adaptive capacity,

ecological vulnerability,

IOD event,

coral triangle,

coral bleaching

\begin{abstract}
This research examines coral reefs vulnerability which threatening its existences and functions by climate change. The ecological vulnerability in Wakatobi (Wangiwangi, Kaledupa, Tomia, and Binongko) was assessed during Indian Ocean Dipole (IOD) event in 2016. Climate exposure was determined using sea surface temperature, chlorophyll-a concentration, and wind speed magnitude; sensitivity was determined using coral susceptibility, fish susceptibility, and macroalgae primary productivity rate; then adaptive capacity was developed by hard coral cover, coral size distribution, coral richness, fish biomass, herbivore diversity, and herbivore grazing relative to algal production. The values of Exposure, Sensitivity, and Adaptive capacity in Wakatobi were $0.93 \pm 0.02,0.42 \pm 0.18$, and $0.44 \pm 0.10$, respectively. Site specific vulnerability scores ranged from 0.52 to 1.60 (mean $0.92 \pm 0.26)$. Binongko was the least vulnerable than other islands. Tomia was observed as the least adaptive capacity and Wangi-wangi was the most bleaching incidents. These results could help coral reefs monitoring priority during the event and then when the event is gone by focusing on the marked islands and sites. Sites that were observed as more vulnerable is urgently need a management strategy to overcome the vulnerability status in the future, such as increasing site adaptability.
\end{abstract}

\section{Introduction}

Coral reefs form a complex habitat, and it provides important environmental services such as food, shelter and coastal protection (Cesar 2002). Disturbances on coral reefs habitat can result in several impacts on coral reef ecosystems and dependent communities, for example, coral bleaching and mortality from increasing sea temperatures can alter the goods and services created by coral reefs, such as the productivity of coral reef fisheries (Graham et al. 2007). The impact of increasing temperature is affecting many species, when there has been a lot of coral bleaching events (Berumen and Pratchett 2006) and the coral invasion diseases

\footnotetext{
* Corresponding Author

E-mail Address: hawis@apps.ipb.ac.id
}

such as sponges (Madduppa et al. 2015). Glynn (1993) indicates that $70 \%$ of coral bleaching reports associated with the report that waters become warmer than normal conditions. In addition to coral bleaching, the increase in sea surface temperatures also makes coral reefs susceptible to disease.

The important existence of coral reefs is threatened by two common factors, human (high and destructive fishing, pollution) and nature (sedimentation and climate change) (McClanahan 2002; Hughes et al. 2003). The exact potential impacts of these threats are still unclear in many cases, making effective conservation difficult. Climate change as the major issue becomes fully evident in 1997-1998 when elevated sea surface temperature (SST) was linked to global warming and a strong El Nino which caused widespread coral bleaching and mortality 
throughout the tropical oceans (Hoegh-Guldberg 1999). As a result of the sea-atmosphere interaction process, the El Niño Southern Oscillation (ENSO) phenomenon has been discussed over a century because of its impact on the global climate that may affect many life aspects such as coral ecosystems. Then in the last decade, another phenomenon sea-atmosphere interaction was discovered and is considered important, namely Indian Ocean Dipole (IOD). A positive IOD indicates SST anomalies, with warmer than normal SSTs over the western basin and cooler than usual SSTs in the eastern basin near Sumatra. Conversely, a negative IOD indicates warmer than normal SSTs over the eastern basin and cooler than usual SSTs in the western tropical Indian Ocean (Saji et al. 1999). In 2016, according to National Oceanic and Atmospheric Administration (NOAA) OISSTv2, the strongest negative IOD in the period since 1980 was occurred (Reynolds et al. 2002), with the highest value of Indian Ocean Dipole Mode index (DMI) was $-1.5^{\circ} \mathrm{C}$. The impact of negative IOD was felt in Wakatobi where sea temperature rose up to $31^{\circ} \mathrm{C}$ degrees in May 2016; this condition made us had to carry out the survey.

Negative IOD is an extreme condition of coral reefs to live. The relationship of these environmental conditions with coral reefs can be seen by looking for the value of its vulnerability. The vulnerability is most often conceptualized as a function of the exposure, sensitivity and adaptive capacity of the perturbed organisms or ecosystems, in an ecological context, the value of vulnerability is referred to as ecological vulnerability. Exposure is the degree to which a system is stressed by climates, such as the magnitude, frequency, and duration of a climatic event such as temperature anomalies or extreme weather events. Sensitivity, in the context of environmental change, is the susceptibility to the harm of a defined component of the system resulting from exposure to stresses (Adger 2006). Adaptive capacity refers specifically to the preconditions that enable adaptation to change (Smit and Wandel 2006).

Vulnerability assessments can be broad or specific. Broad vulnerability assessments focus on multiple sectors or globally defined policy areas, but the implications for policy interventions are often not focused enough to determine implementation needs. Specific vulnerability assessments target identified problems to recommend the specific intervention and scale of policies needed to reduce vulnerability (Ionescu et al. 2009). For example, broad assessments of threats to coral reefs, such as the World Resource Institute's Reefs at Risk project (Burke et al. 2011), can lack the specific recommendations needed by policymakers or governments to understand and manage environmental change as it relates to immediate socio-economic problems.

This research is going to be the specific assessment, located in Wakatobi. Wakatobi is the second largest marine national park in Indonesia with an area of 1.39 million ha and is at the center of the world biodiversity. It was noted that there are 396 species of coral reefs hermatypic scleractinian coming from 68 genus and 15 families (Turak 2003), besides there are ten species of non-scleractinian or ahermatypic hard coral and 28 genera soft coral (Pet-Soede and Erdmann 2004), so Wakatobi is worthy of being a research location.

Knowledge of the vulnerability of coral reefs during IOD negative could be a cornerstone of environmental management for conservation activities, a base of an early warning mechanism preventing negative impacts, and additional knowledge about the relationship of environmental changes and the ecosystem in it.

The aim of this study is to develop and test a methodology for assessing climate change vulnerability of coral reef ecosystems. The study is focused on a small scale in Wakatobi Waters, and then provides information that might minimize vulnerability.

\section{Materials and Methods}

\subsection{Study Site}

Surveys were conducted in the Wakatobi National Park Southeast Sulawesi. Indonesia on April 2016. This study was held on the main island of Wakatobi, and they were Wangi-wangi, Kaledupa, Tomia, and Binongko. There are four stations in each of the major islands that represent each of the cardinal directions (north, south, west, and east), but unfortunately due to ocean currents are very strong, a survey was not conducted in the eastern part of the Binongko Island (Figure 1). The ecological vulnerability of coral reefs was investigated at representative shallow coral reef sites (<15 deep) (McClanahan et al. 2007a). Most study sites were reef edge sites (about 5 m deep), while one site on Kaledupa was surveyed on fringing reef area ( 3 $m$ deep). However, depth had little effect on the trends of vulnerability (McClanahan et al. 2007a). 


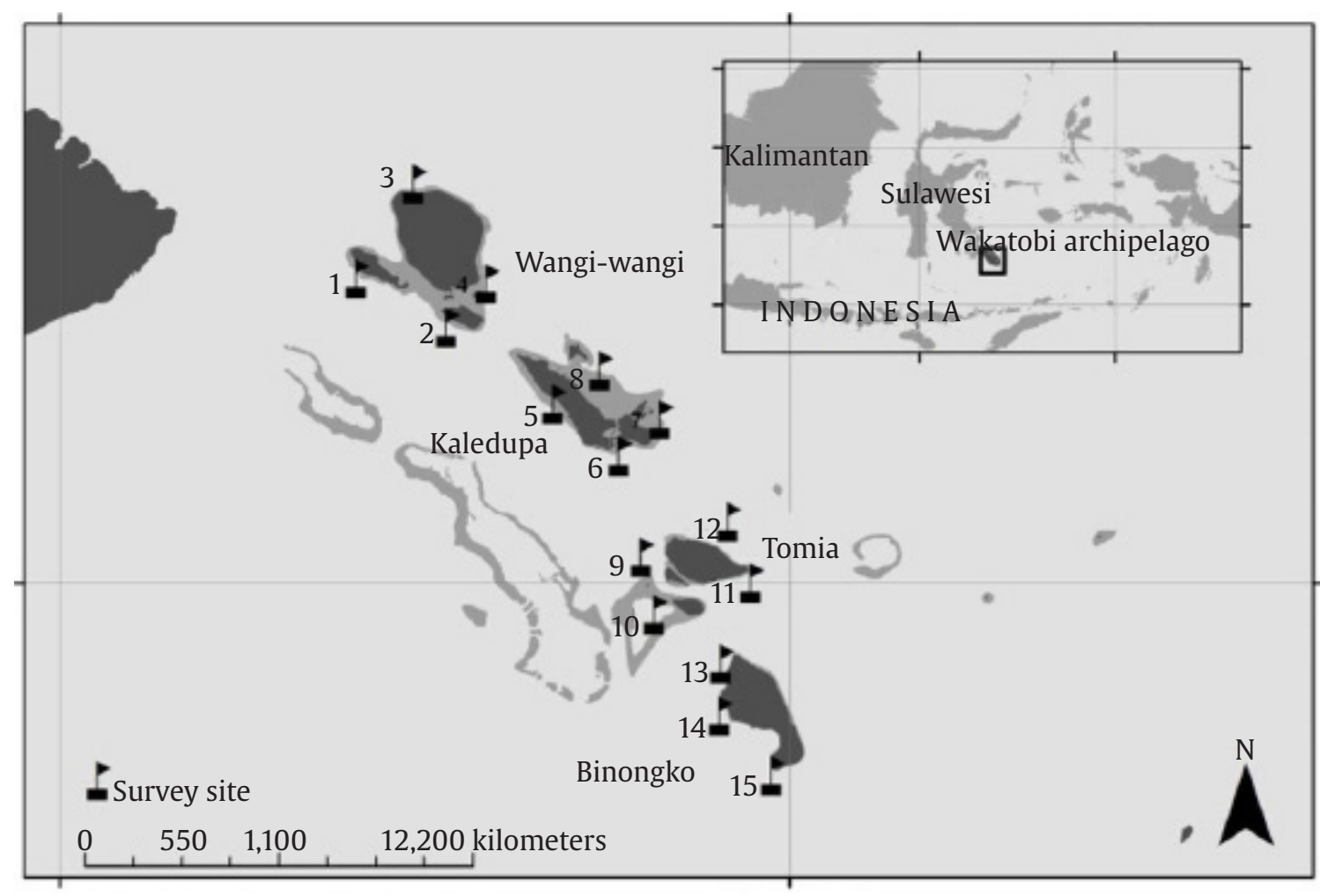

Figure 1. Showing islands of Wangi-wangi, Kaledupa, Tomia and Binongko, and survey sites (numbers)

\subsection{Surveys Methods and Data Analysis}

Several things were prepared to support field data acquisition such as Self Contained Underwater Breathing Apparatus (SCUBA), roll meter, research vessel, pencil, waterproof paper, and underwater camera. Secondary data was obtained at www.indeso.web.id and apps. ecmwf.int. Data analysis was done using Microsoft Office, FERRET and ArcMaps 10 software.

Coral reef habitat was quantified using $20 \mathrm{~m}$ line intercept transect (LIT) that spread in line with the beach ( $\sim 5 \mathrm{~m}$ depth), each survey station laid eight transects. The observation was conducted by one person to measure the lengths of major benthic components (hard coral, soft coral, macroalgae, etc) under each transects line to the nearest centimeter. Hard corals were identified to genus, and the genus Porites was subdivided into two distinct morphological groups: massive Porites and branching Porites.

Hard coral communities were also evaluated using roving observer surveys to quantify community structure over a larger reef area. The observer was haphazardly selecting coral colonies and classifying them into seven categories of coral bleaching, which allows scaling of the bleaching response by taxon and site (Siebeck et al. 2006). Observers moved in chosen directions and distances and periodically or haphazardly selected areas.
All coral colonies within $1 \mathrm{~m}^{2}$ transect were identified to the genus, counted, and assigned into 7 categories of bleaching intensity: $c_{0}=$ normal, $c_{1}=$ pale live coral, $c_{2}=0-20 \%, c_{3}=20-40 \%, c_{4}=40-60 \%, c_{5}=60-80 \%$ and $c_{6}=80-$ 100\% (McClanahan et al. 2007a).

The fish visual census is the most suitable method for coral reef fish monitoring. The survey was conducted on $50 \mathrm{~m}$ long transects with $2.5 \mathrm{~m}$ for each side and three replicates at each site (English et al. 1997). Along transects, each fish or fish colony was identified to the lowest taxonomic unit possible by the surveyor, and the determined size of each fish was recorded to quantify the specific biomass. We also determine species richness and abundances of the fish community from the number of observed species in four species families (Acanthuridae, Chaetodontidae, Labridae, and Scaridae). Species richness determines were expressed as the number of species per $250 \mathrm{~m}^{2}$ (Cinner et al. 2013).

Sea Surface Temperature (SST) and Chlorophyll-a concentration derived variables were obtained from Infrastructure Development of Space Oceanography (INDESO) catalog. Inside INDESO catalog, we use a product that covers four parameters (SST and chlorophyll-a concentration are two of them) which was computed by satellite sensors. The data are gap-free (no clouds), defined on a $0.83^{\circ}$ horizontal 
resolution grid and available daily from 28th December 2013. In this study, we collect SST and chlorophyll-a data from April 2016 to May 2016.

Sea surface wind speed $\left(\mathrm{m} \mathrm{s}^{-1}\right)$ data was sourced from the European Centre for Medium-Range Weather Forecasts (ECMWF). The data is $10 \mathrm{~m}$ above sea level with $0.125^{\circ}$ resolution and available in zonal-meridional (uv) component. We download both u-component and v-component at $12 \mathrm{PM}$ on April to May 2016.

Coral bleaching is a direct impact of IOD events, to calculate how much bleaching that occurs in a site, we can use prevalence $(P)$ variables following equation below:

$$
\mathrm{P}=\frac{\text { Bleaching cover }}{\text { Coral cover }} \times 100 \%
$$

\subsubsection{Exposure}

Exposure in this study was composited by three chosen stressors which are considered to be climatic drivers of coral reef exposure; they were Sea Surface Temperature (SST), wind speed magnitude, and chlorophyll-a concentration. SST is believed to be the dominant factor causing coral bleaching and mortality (McClanahan 2007b) while, as wind speed magnitude decreases, vertical-mixing also decreases, resulting in decreased evaporative cooling and transfer of deeper cool water, which increases the likelihood of thermal stress on corals (Hoegh-Guldberg 1999). Then chlorophyll-a as stress reinforcing or exacerbating interactive stressors because they could undermine the resilience of the coral reef ecosystem through either undermining physiological homeostasis or the recovery processes after disturbance (Wooldridge 2009), also was associated with eutrophication.

All the data acquired from both INDESO and ECMWF is visualized into spatial distribution map using ArcMap 10 software. Therefore all data is available as map with a single data for evey pixel (as result of natural neighbor interpolation). Several points will be taken from the maps to represent each island, and then is normalized following equation below (Maina et al. 2011):

$$
\mu(x)=\left\{\begin{array}{c}
0, x \leq x_{a} \\
2\left(\frac{x-x_{a}}{x_{b}-x_{a}}\right)^{2}, x_{a} \leq x \leq \frac{x_{a}+x_{b}}{2} \\
1-2\left(\frac{x-x_{b}}{x_{b}-x_{a}}\right)^{2}, \frac{x_{a}+x_{b}}{2} \leq x \leq x_{b} \\
1, x \geq x_{b}
\end{array}\right\}
$$

$$
\mu(x)=\left\{\begin{array}{c}
1, x \leq x_{a} \\
1-2\left(\frac{x-x_{b}}{x_{b}-x_{a}}\right)^{2}, x_{a} \leq x \leq \frac{x_{a}+x_{b}}{2} \\
2\left(\frac{x-x_{a}}{x_{b}-x_{a}}\right)^{2}, \frac{x_{a}+x_{b}}{2} \leq x \leq x_{b} \\
0, x \geq x_{b}
\end{array}\right\}
$$

Where $x_{a}$ and $x_{b}$ respectively are control values to the lower and upper bound of stressor values, and $\mu$ is the normalization result. These lower and upper bound values are calculated for each variable as the mean value minus or plus two standard deviation, respectively. SST and Chl-a concentration variables were normalized using an increasing curve (Eq. 2), and wind magnitude variables were normalized using a decreasing curve (Eq. 3).

\subsubsection{Sensitivity}

The sensitivity of a site to coral bleaching was determined using three indicators: the susceptibility of the coral community to bleaching, susceptibility of the fish community to population declines associated with coral habitat loss from bleaching and macroalgae primary productivity associated with community shifting potential. Coral bleaching susceptibility was determined from the coral community structure determined by roving observer surveys, weighted by the regional taxa-specific bleaching sensitivity of each genus. The bleaching response of each genus in the Wakatobi Archipelago was calculated to following equation (McClanahan et al. 2007a):

$$
\begin{gathered}
\mathrm{BR}=\frac{0 \mathrm{C}_{0}+1 \mathrm{C}_{1}+2 \mathrm{C}_{2}+3 \mathrm{C}_{3}+4 \mathrm{C}_{4}+5 \mathrm{C}_{5}+6 \mathrm{C}_{6}}{6} \\
\mathrm{BR} \text { : taxon-specific bleaching response } \\
\mathrm{C}_{\mathrm{n}} \quad: \text { categories of bleaching intensity }
\end{gathered}
$$

Sum all colonies in each category and apply the above formula (Eq. 4) gave the site-specific BR. Bleaching susceptibility of coral communities was determined at each site based on the relative abundance of coral taxa and their observed bleaching response (Cinner et al. 2013).

$$
\text { Coral bleach.suscp. }=\sum_{i}^{n}\left(\mathrm{RA}_{i} \times \mathrm{BR} i\right)
$$

RA : relative abundance of each coral taxon

BR : taxon-specific bleaching response 
Reef fish susceptibility at each site was similar to the coral bleaching susceptibility index, the relative abundance of each species, $\mathrm{j}$, was multiplied by a taxonspecific vulnerability index $\left(\mathrm{V}_{\text {climate }}\right)$ and then summed across all species observed at a site to provide a sitelevel estimation. This estimation of the susceptibility of the reef fish assemblage to habitat loss is associated with coral bleaching (Eq. 6). Taxon-specific bleaching response was assessed by (Graham et al. 2011) from four variables that are related to fish population declines following coral bleaching and mortality: diet specialization, habitat specialization, recruitment specialization to live coral and body size.

Fish suscep. to bleaching $=\sum_{j}^{n}\left(\mathrm{RA}_{j} \times \mathrm{V}_{\text {climate } j}\right)$

RA : relative abundance of each species

$\mathrm{V}_{\text {climate }}$ : taxon-specific bleaching response

Coral and fish are not the only components affected by climate shock; another variable is vegetation life such as macroalgae. More macroalgae can give negative impact to ecosystems and associate with coral community shifting. The primary productivity rate of the macroalgae community on coral reefs was determined as a gross algal production of $196 \mathrm{~kg} \mathrm{ha}^{-1}$ day $^{-1}$ at $100 \%$ algal cover (McClanahan 1995) multiplied by the observed average percent cover of algae at each site from coral habitat transects.

\subsubsection{Adaptive Capacity}

Ecological recovery potential was determined using six ecological indicators they were the hard coral cover, coral size distribution, coral richness, fish biomass, herbivore diversity, and herbivore grazing relative to algal production (Cinner et al. 2013).

Coral cover is linked to resilience and recovery increasing (Cinner et al. 2013). The hard coral cover was determined as the average percent cover of live coral from replicate transects at each site. There is scientific evidence that evenness across size classes increases recovery. An even distribution across size classes indicates a recovering community of coral recruits, juveniles, and adult colony. An under-representation of juvenile colonies describes a recruitment failure and suppresses recovery rate (Meesters et al. 2001). Also, the lack of large adult coral colonies may limit the stock of spawning as well as an indicator of the environmental stresses that cause partial colonies and fragmentation deaths (Lins and Débora 2006). The coral size distribution was determined as the coefficient of variation (CV) of the average size of each coral genus at a site.

$$
\mathrm{CV}=\frac{\text { Mean size }}{\text { Standard deviation of size }} \times 100 \%
$$

Coral richness is expected to promote recovery; however; there is limited evidence that coral diversity promotes recovery following disturbance. Coral richness was calculated as the number of genera observed in the community (Ives and Carpenter 2007).

Fish biomass indicates stock, potential growth, and ecological metabolism. Fish biomass density ( kg $\mathrm{ha}^{-1}$ ) was calculated as total wet weight of all surveyed reef fishes from replicate $3 \times 50 \mathrm{~m}$ belt transects at each site. Taxon-specific biomass is obtained with a body length approach follows the following equation (Effendie 1979).

$$
\begin{array}{ll} 
& \mathrm{W}=\mathrm{aL}^{\mathrm{b}} \\
\mathrm{W} & \text { : weight }(\mathrm{gr}) \\
\mathrm{L} & \text { : total length }(\mathrm{cm}) \\
\mathrm{a} \text { and } \mathrm{b} & : \text { taxon specific constant }
\end{array}
$$

Experimental evidence indicates that the presence of a diverse guild and functional groups of herbivores can enhance coral recovery. Herbivore diversity was determined from energetic-based grazing rate of three herbivorous fish families (Acanthuridae - surgeonfishes; Scaridae - parrotfishes; Siganidae - rabbitfishes)(Cinner et al. 2013). Herbivore diversity was determined using Simpson diversity index.

$$
\mathrm{D}=\sum_{\mathrm{i}}^{\mathrm{n}} \mathrm{p}_{\mathrm{i}}^{2}
$$

$$
\begin{aligned}
& \mathrm{D} \\
& \mathrm{p}_{\mathrm{i}} \quad \text { : herbivore diversity } \\
& \text { a specific-taxon individual/total herbivore in }
\end{aligned}
$$

Most studies have linked herbivore increasing may reduce macroalgal cover and increase coral recruitment. Some studies also have shown that increases in herbivore biomass led to a reversal in the reef trajectory from one of coral decline to coral recovery (Cinner et al. 2013). Herbivore grazing relative to algal production was quantified as the 
difference between total herbivore grazing rates on algae $\left(\mathrm{kg} \mathrm{ha}^{-1}\right.$ day $\left.^{-1}\right)$ and rate of algal production $(\mathrm{kg}$ ha ${ }^{-1}$ day $^{-1}$ ) at each site.

Herbivorous fishes have been reported to consume $22 \%$ of their body mass per day (McClanahan 1992), and then the total herbivore grazing rates on algae were $22 \%$ of herbivore biomass. To determine the rate of algal production we used an determine of gross algal production of $196 \mathrm{~kg} \mathrm{ha}^{-1}$ day $^{-1}$ at $100 \%$ algal cover (McClanahan 1995) multiplied by the observed average percent cover of algae at each site from coral habitat transects.

\subsubsection{Vulnerability}

The potential impact of IOD negative on an ecosystem is the results of physical exposure to climatic stressors combined with the sensitivity of those ecosystems. Whether these potential impacts are fully experienced in the long term depends on the potential of the ecosystem to recover its basic structure and function as responses to impacts Figure 2. The combination of exposure (E), sensitivity (S) and adaptive capacity (Ac) result in a degree of vulnerability. This vulnerability (V) can be explained by the following equation:

$$
\mathrm{V}=\mathrm{E}+\mathrm{S}-\mathrm{Ac}
$$

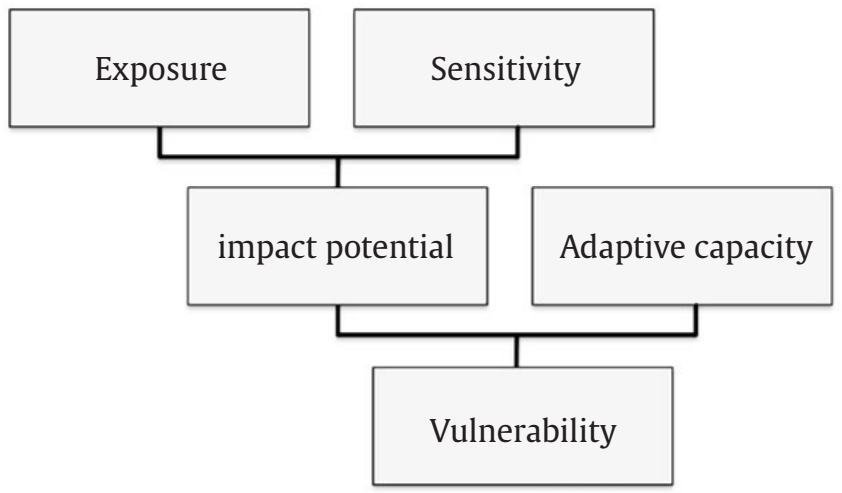

Figure 2. Intergovernmental Panel on Climate Change (IPCC) conceptual framework of vulnerability to climate change. (Cinner et al. 2013)

All of the indicators (excluded exposure components) used in this calculation were standardized based on maximum values in the dataset and placed on a scale of zero to one using the following conversion:

$$
S=\frac{X-X_{\min }}{X_{\max }-X_{\min }}
$$

$S \quad$ : standardized values

$X \quad$ : value before standardization

$X_{\max } \quad$ : maximum values in the dataset

$X_{\min } \quad$ : minimum values in the dataset

In this way, the maximum value of each index was set to a relative value of one. By standardizing within these analyses, these calculated values were relative and only meaningful as they relate to this set of data (Hughes et al. 2012). The result then weighted based on the scientific evidence supporting its importance (Table 1) and is defined by experts judgment. Every weighted variable then was calculated using Eq. 10.

\section{Results}

An extreme IOD event happens and gives its impact in Wakatobi. Some coral bleaching was spotted during a survey. Coral reefs ecosystems in Wakatobi gives bleaching prevalence values range from $8.09-29.94 \%$ (mean $16.11 \pm 3.67 \%$, Figure 3 ). The data shows something is affecting the coral reefs ecosystems.

\subsection{Exposure}

Analyses of the partial and overall exposure from the four major island indicate as highly exposed to climate shock with value more than $0.9(\mathrm{~F}=0.58, \mathrm{P}$ $=0.63$, Figure 4$)$, the exposure value range from 0.91

Table 1. Weighting of vulnerability indicators $(0-1)$

\begin{tabular}{lc}
\hline Indicators & Weight \\
\hline Exposure & \\
Sea surface temperature & 0.64 \\
Wind speed magnitude & 0.22 \\
Chlorophyll-a concentration & 0.14 \\
\hline Sensitivity & \\
Coral bleaching susceptibility & 0.45 \\
Fish susceptibility to bleaching & 0.36 \\
Macroalgae primary productivity rate & 0.19 \\
\hline Adaptive capacity & \\
Hard coral cover & 0.13 \\
Coral size distribution & 0.14 \\
Coral richness & 0.14 \\
Fish biomass density & 0.26 \\
Herbivore diversity & 0.14 \\
Herbivore grazing relative to algal production & 0.19 \\
\hline
\end{tabular}




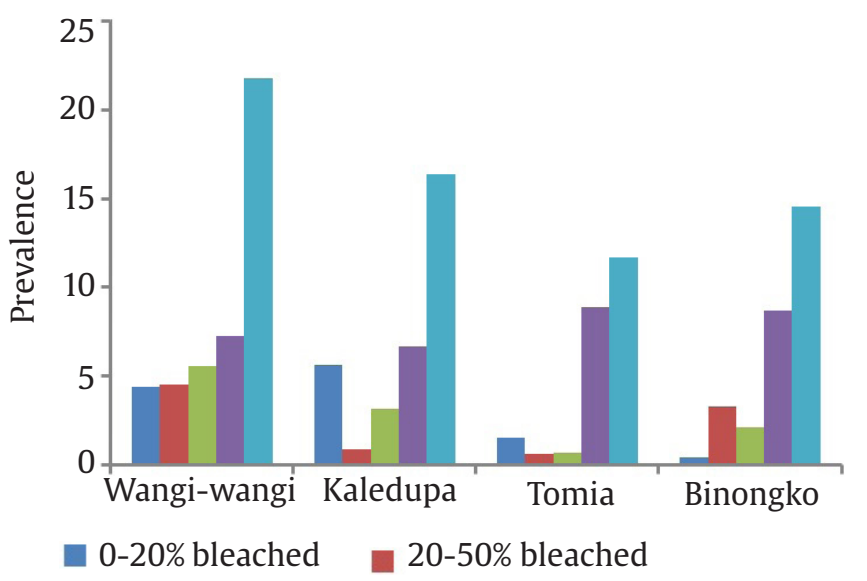

80-100\% bleached $\square$ Total $50-80 \%$ bleached

Figure 3. Coral bleaching prevalence between islands in Wakatobi

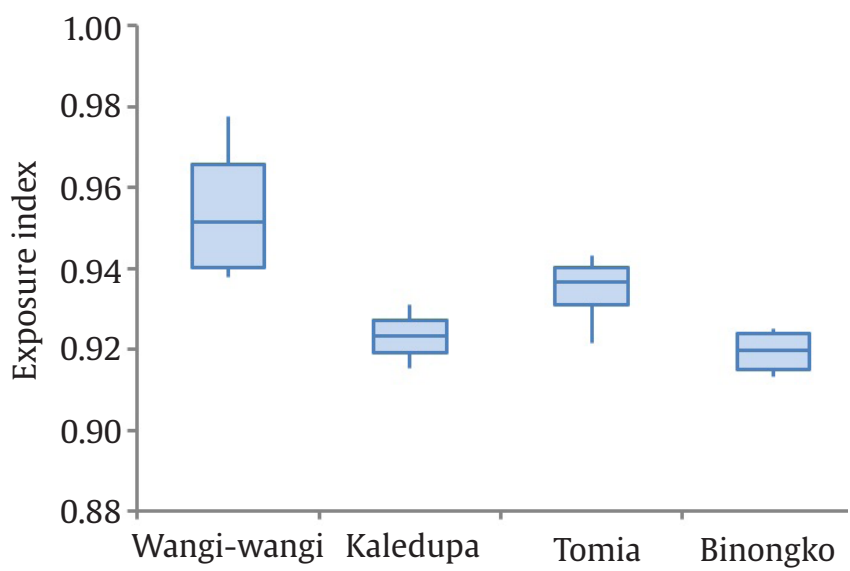

Figure 4. Exposure index between islands in Wakatobi

to 0.97 (mean $0.93 \pm 0.02$; B.1). There is no such a big difference between the four islands because they get more or less the same exposure associated with the small scale of research. This exposure measure alone will not have predictive power in determining responses to the environment, which requires the sensitivity and adaptive capacity of the organisms but does provide a basis for understanding the forces that these organisms face.

The value of chlorophyll-a concentration is in the range between $0.12-4.74 \mathrm{mg} \mathrm{m}^{-3}$ (mean $0.87 \pm 0.98 \mathrm{mg}$ $\mathrm{m}^{-3}$ ), one final variable wind speed magnitude observed data ranged 3.01 to $3.77 \mathrm{~ms}^{-1}$ (mean $3.39 \pm 0.23 \mathrm{~ms}^{-1}$ ), this data serves as the exposure-reducing factor. The wind speed magnitude data acquired is quite large and good for water mass mixing process (C3).

\subsection{Sensitivity}

Site-specific sensitivity scores ranged from 0.21 to 0.92 (mean $0.42 \pm 0.18$; Figure 5). One way ANOVA test within four major islands in Wakatobi based its sensitivity shown that at least two population have a different mean $(\mathrm{F}=3.79, \mathrm{P}=0.04)$. There is a wide value distribution within the data set of sensitivity; this shows that with relatively similar exposure values, the site provides a different response. This sensitivity index result didn't consider these islands are sensitive or not because the index values are the result of standardization only meaningful as they relate to this set of data. The results only show which island is more sensitive or less sensitive to the other island.

Coral susceptibility index between all islands on Wakatobi was same (one-way ANOVA, $\mathrm{F}=0.04, \mathrm{P}=$ 0.99; Figure 6), other words the coral within Wakatobi were affected equally by climate disturbance. Important things to remember although there is no real difference between the susceptibility values, the effect on the sensitivity can be more diverse because the values used in the sensitivity has been standardized.

This study observed, genus Acropora (mean 7.8 \pm 1.3 ), Pocillopora (mean 6.7 \pm 1.0 ), and branching Porites (mean 5.4 \pm 0.9 ) were among 3 genus with the highest susceptibility values (D1).

One way ANOVA statistical tests performed to see whether there are differences mean between the islands and the results showed that all or at least two of the island has a different mean $(\mathrm{F}=4.91, \mathrm{P}=0.03)$. Fish susceptibility index in Wakatobi showed a downward trend as more distant with Wangi-wangi Island that has the highest susceptibility values (Figure 7).

The last variable of the sensitivity compiler is macroalgae primary productivity rate, the value range from 0.06 to $11.08 \mathrm{~kg} \mathrm{ha}^{-1} \mathrm{day}^{-1}$ (mean $3.56 \pm 3.05 \mathrm{~kg}$ ha $^{-1}$ day $^{-1}$, Figure 8 ). One way ANOVA test shows that there's a quite different productivity rate between the four major island $(\mathrm{F}=4.46, \mathrm{P}=0.03)$. As can be seen in Figure 8 there is a large standard deviation value on Kaledupa Island, and this is very normal considering several locations around Kaledupa has a value of chlorophyll-a that relatively high. The high values of this productivity rate on Kaledupa Island may become the main factors of its high sensitivity values.

The high value of chlorophyll-a concentration which is followed by the rate of primary productivity is not explored in depth in this study, but the possibility (weighing unmeasured field observations) is closely related to human activity around the site (requires further validation).

\subsection{Adaptive Capacity}

Site-specific sensitivity scores ranged from 0.25 to 0.61 (mean $0.44 \pm 0.10 \mathrm{sd}$; Figure 9). The highest adaptive capacity between the four major islands is Binongko, 


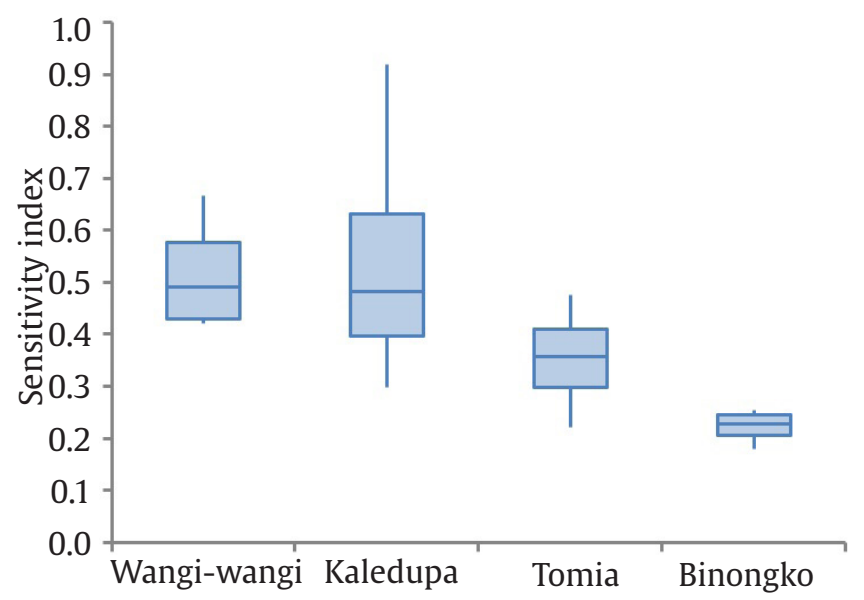

Figure 5. Sensitivity index between islands in Wakatobi

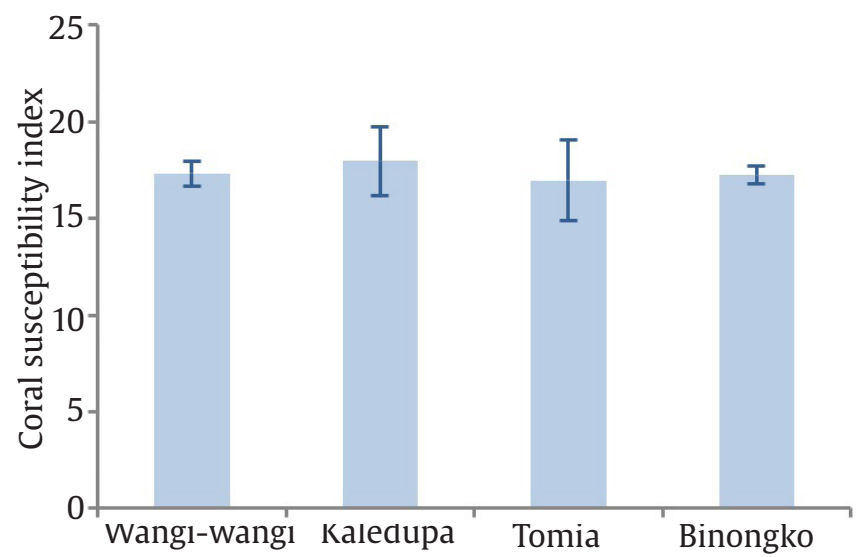

Figure 6. Coral susceptibility index between islands in Wakatobi

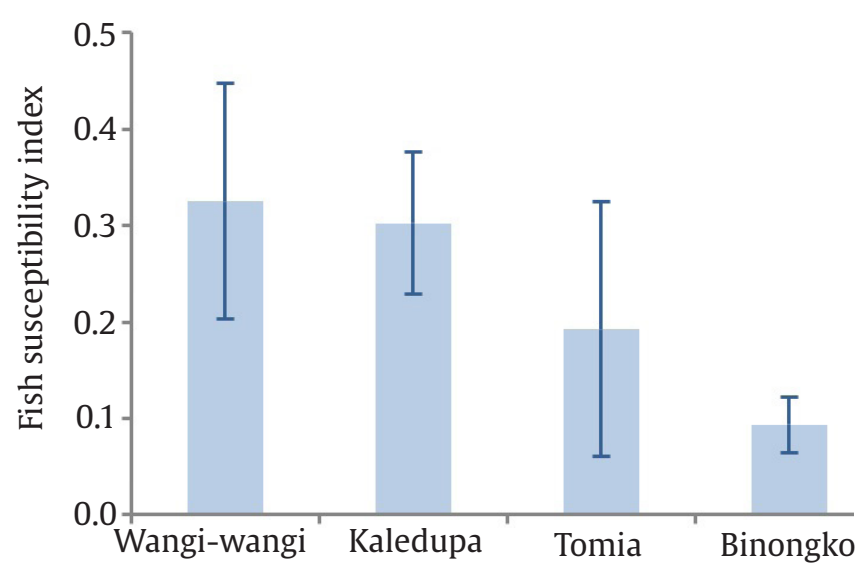

Figure 7. Fish susceptibility index between islands in Wakatobi waters

means that Binongko has a better recovery potential during climate disturbance rather than the other three major islands, while the lowest recovery potential is on Tomia Island, which means Tomia will require more attention and management to help it recover

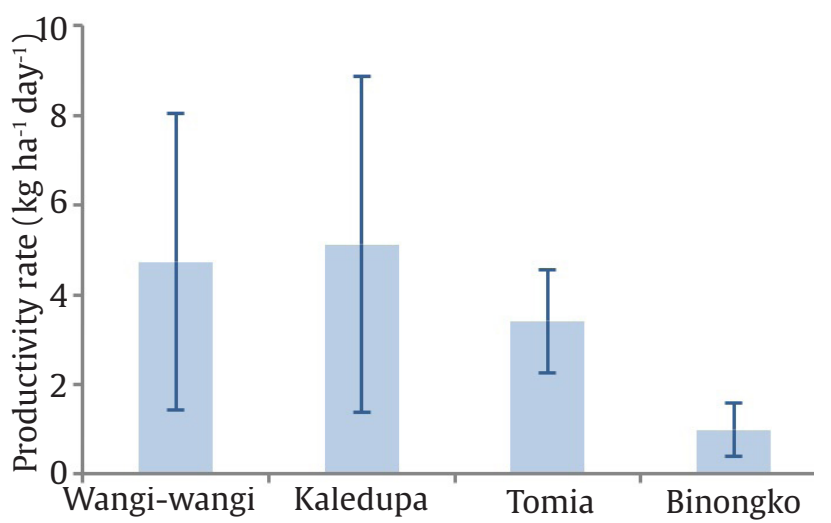

Figure 8. Macroalgae primary productivity rate between islands in Wakatobi

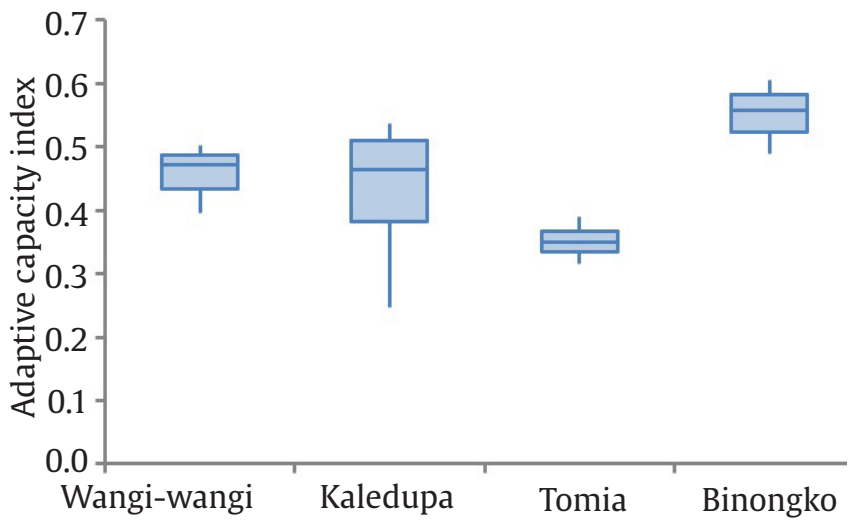

Figure 9. Adaptive capacity index between islands in Wakatobi

from climate shock. One way ANOVA test within four major islands in Wakatobi based its adaptive capacity shown that three other major islands especially Tomia will need a better attention than Binongko Island ( $F$ $=7.93, \mathrm{P}=0.008$ ).

The ability of a site to recover depends on several factors, in this study, we focused on six factors: hard coral cover, coral size distribution, coral richness, fish biomass, herbivore diversity, and herbivore grazing relative to algal production (Figure 10). Figure 10a shows that the lowest hard coral cover was found at Tomia, benthic cover at the observation site at Tomia more dominated by soft than hard coral reef, it affects the ability of the site to recover. Tomia as the lowest average coral cover ranged from 11.87 to $41 \%$ (mean $32.25 \pm 13.72$ ), followed by Binongko (ranged 39.63 to 41.37, mean 40.21 \pm 1.01 ) afterwards Kaledupa (ranged 15.13 to 56.00 , mean $40.43 \pm 17.83$ ) and the highest hard coral cover is in Wangi-wangi ranged between 45.13 to 56.25 (mean $52.21 \pm 4.89$ ). 


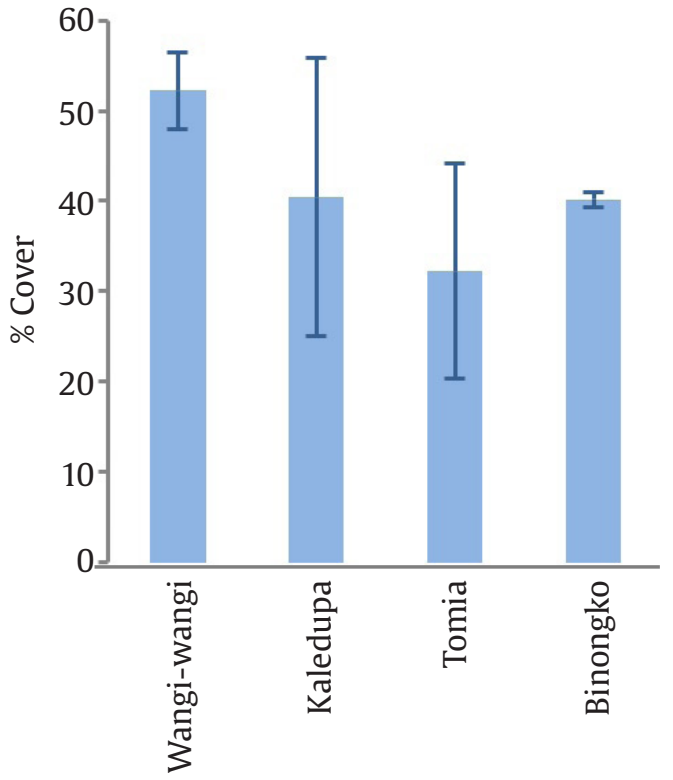

C

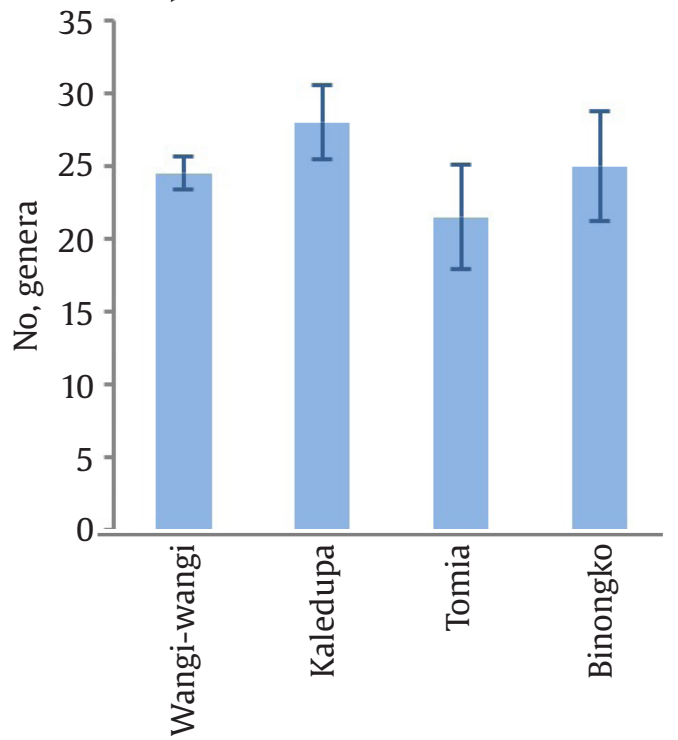

e

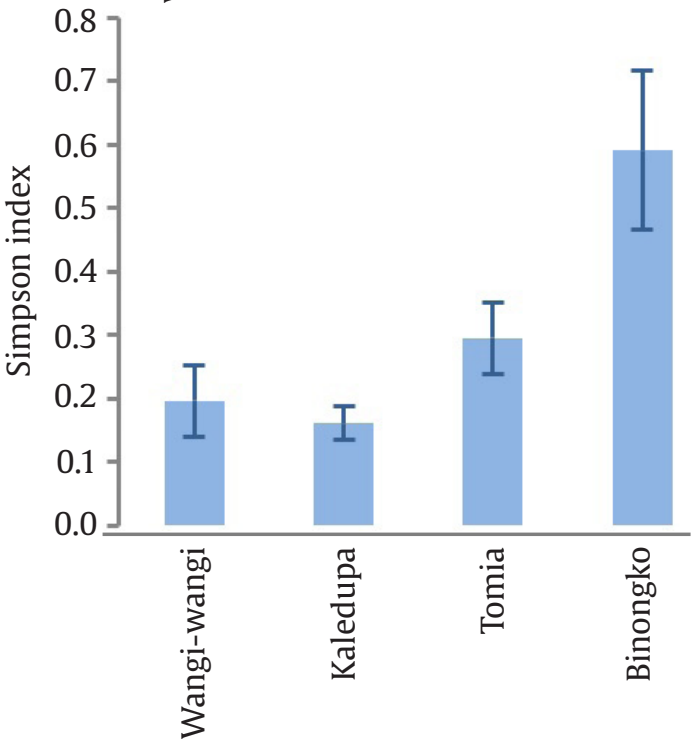

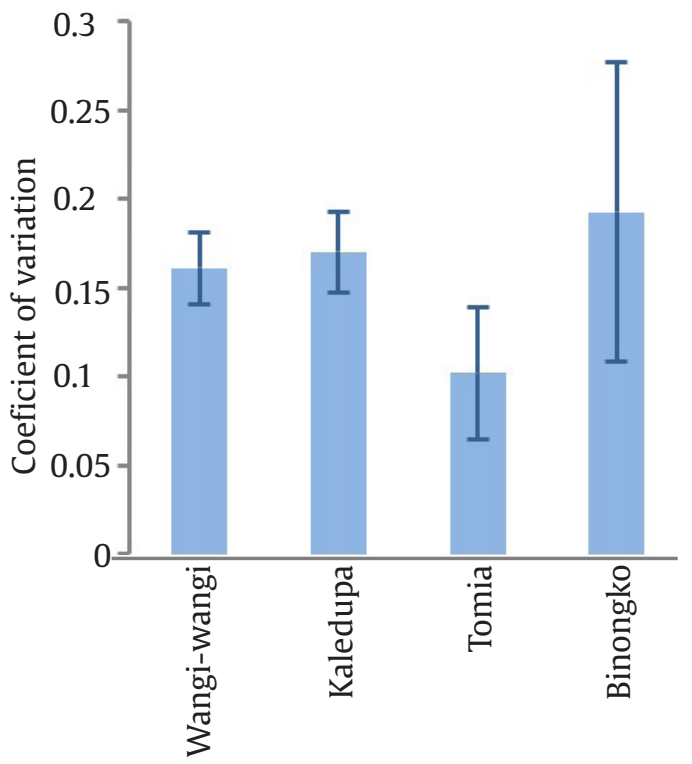

d

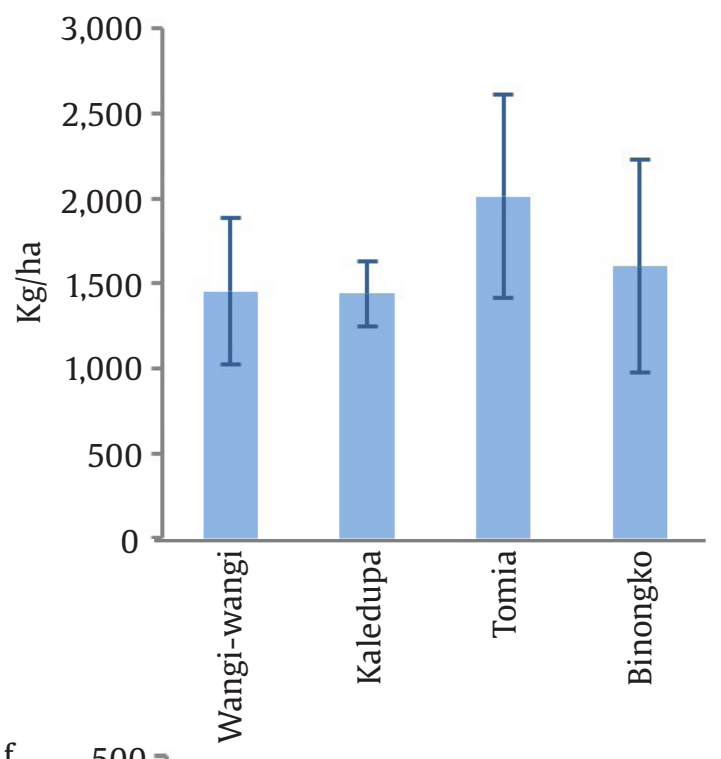

f

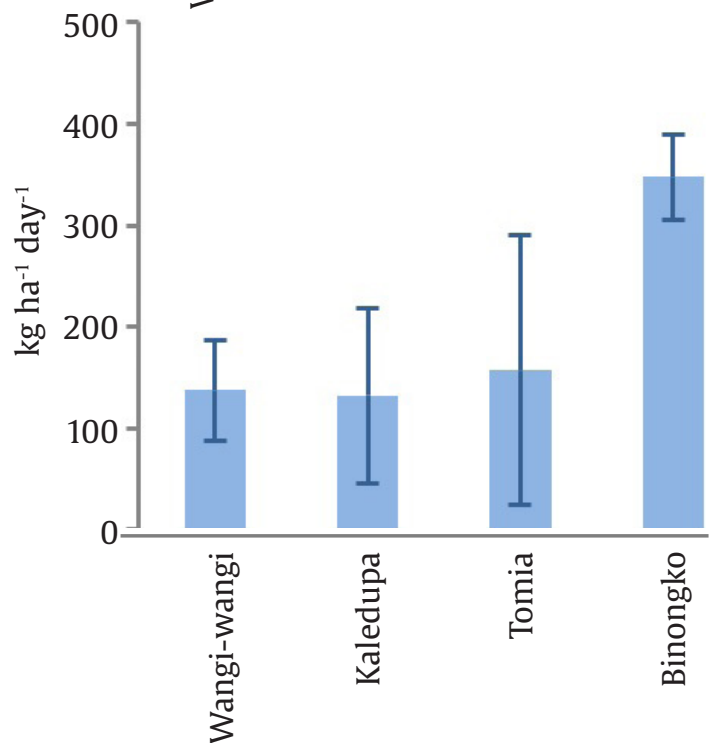

Figure 10. Factors that determine the ability of a site to recover. (a) Percent coral cover, (b) coral size distribution, (c) coral richness, (d) fish biomass, (e) herbivore diversity, and (f) herbivore grazing relative to algal production 
Binongko displays a wider variation in size compared to other locations with average values $0.19 \pm 0.1$, followed by Kaledupa (mean $0.17 \pm 0.03$ ), then Wangi-wangi (mean $0.16 \pm 0.02$ ), and the island with the lowest variation is Tomia $(0.10 \pm 0.04)$, briefly in terms of size variation Tomia is considered less than the other islands (Figure 10b).

The coral richness of Wangi-wangi, Kaledupa, Tomia, dan Binongko in the sequence is $24.50 \pm 1.12,28 \pm 2.55$, $21.5 \pm 3.57$, and $25 \pm 3.74$ (Figure 10c). Figure 10d shows that fish biomass value is not highly versatile; the fish biomass value ranged from 740.80 to $2959.45 \mathrm{~kg} / \mathrm{ha}$. The highest to the lowest fish biomass respectively is Tomia (2011.03 $\pm 600.12 \mathrm{~kg} / \mathrm{ha})$, Binongko (1600.67 \pm 628.41 ), and both Wangi-wangi (1452.66 $\pm 430.61 \mathrm{~kg} / \mathrm{ha})$ and Kaledupa ( $1438.78 \pm 188.85 \mathrm{~kg} / \mathrm{ha}$ ).

Figure 10e shows the diversity of fish herbivores values ranged from 0.025 to 0.367 , the highest to the lowest diversity respectively is Binongko (0.197 \pm 0.125$)$, Tomia $(0.059 \pm 0.111)$, and both Wangi-wangi $(0.039 \pm 0.011 \mathrm{~kg} / \mathrm{ha})$ and Kaledupa $(0.032 \pm 0.005 \mathrm{~kg} / \mathrm{ha})$.

\subsection{Ecological Vulnerability}

The wide range of ecological condition across the 15 coral reef sites in Wakatobi Waters led to a considerable spread in the composite ecological vulnerability index. Site-specific vulnerability scores ranged from 0.52 to 1.60 (mean $0.92 \pm 0.26$ ). In general Wangi-wangi, Kaledupa, and Tomia were marginally more vulnerable than Binongko (one-way ANOVA, $\mathrm{F}=8.84, \mathrm{P}=0.006$; Figure 11 ). Respectively Wangiwangi, Kaledupa, and Tomia scores are $1.03 \pm 0.17$, $1.03 \pm 0.40$, and $0.93 \pm 0.10$, these values are absolutely higher than Binongko Island that has vulnerability values $0.58 \pm 0.09$. As what describe earlier that this vulnerability values only matter if it is compared each other, the values don't tell if it is objectively very vulnerable or not. Don't mean these results are unimportant because these results are particularly useful for comparing certain areas for better management, with more areas of study will surely yield more useful results.

The three facets of ecological vulnerability (exposure, sensitivity, and recovery potential) were not strongly correlated, suggesting these different components are not related (Pearson correlation coefficients: exposure to sensitivity, $r=0.19$, exposure to adaptive capacity, $\mathrm{r}=-0.29$, sensitivity to recovery potential, $r=-0.48$ ). These component scores for each location indicated that there was no single driver of vulnerability or a single underlying mechanism

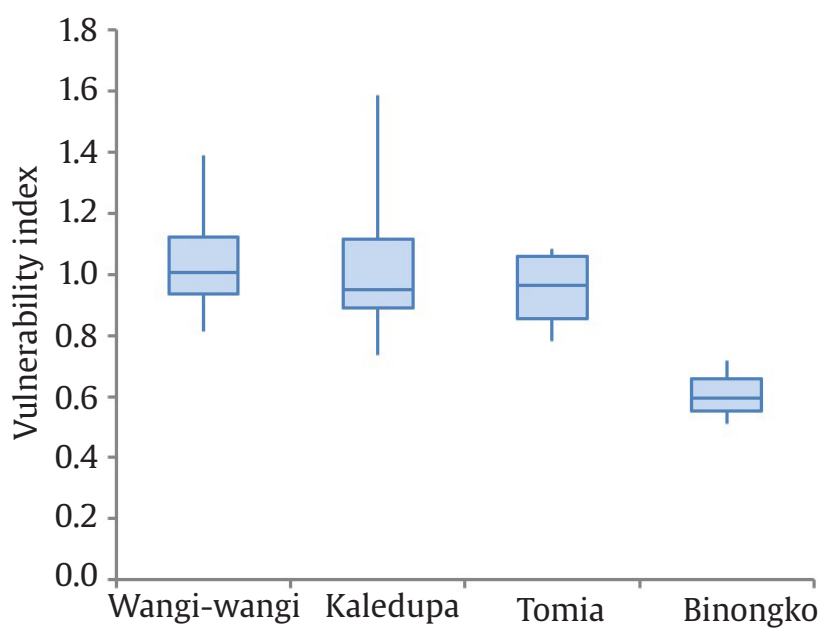

Figure 11. Vulnerability between islands in Wakatobi

that makes a site particularly vulnerable; rather, the location experienced vulnerability as the result of a combination of adaptive capacity, sensitivity and exposure (Figure 12).

\section{Discussion}

Exposure value obtained is a function of SST, chlorophyll-a concentration and magnitude of wind speed. There is no such a big difference between the four islands from their overall exposure because they get more or less the same exposure associated with the small scale of research. This exposure measure alone will not have predictive power in determining responses to the environment, which requires the sensitivity and adaptive capacity of the organisms but does provide a basis for understanding the forces that these organisms face. According to Sukarno et al. (1983), the best temperatures for coral growth ranged from $25-29^{\circ} \mathrm{C}$. The value of SST around the four main islands ranging from $29.92-29.98^{\circ} \mathrm{C}$, which means the observed temperature is slightly higher than the ideal temperature for coral to grow. The value of chlorophyll-a concentration is in the range between $0.12-4.74 \mathrm{mg} \mathrm{m}^{-3}$ (mean $0.87 \pm 0.98 \mathrm{mg} \mathrm{m}^{-3}$ ), the high standard deviation value due to the distribution of chlorophyll-a concentration is closely related to oceanographic condition of waters (HendersonSeller and Markland 1987), where around Kaledupa there are areas with a relatively higher concentration of chlorophyll compared to other regions (C2) but how and what the cause is not traced in detail, because in this study the value of chlorophyll is only used to see the potential of eutrophication. 


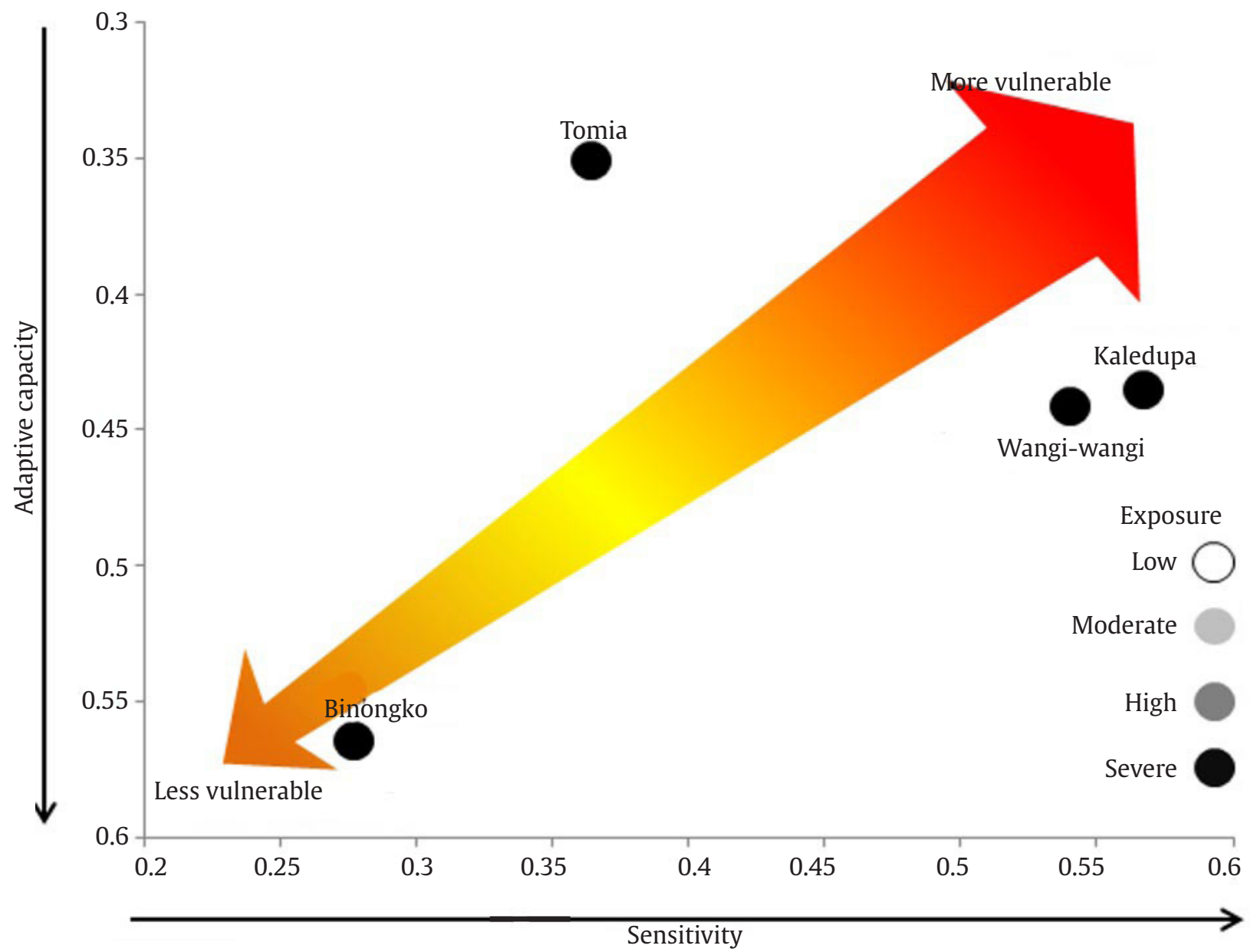

Figure 12. Distributions of coral reefs vulnerability components between islands in Wakatobi

Susceptibility value of the site is closely associated with the susceptibility of each taxon that existed at the site since the value of the susceptibility of the site is the sum of each taxon value, it is also supported by Marshal and Baird (2000) that said the taxonomic composition of the coral assemblage is another strong driver of variation in bleaching at a reef scale. This is because consistent differences have been documented in the susceptibility of coral taxa to bleaching (Loya 2001). In most studies to date, branching colonies of the genera Acropora and Pocillopora have been reported to bleach much more severely relative to other growth forms and coral genera, particularly slow-growing massive species (Mcclanahan et al. 2004), the fact is also demonstrated in this study, which genus Acropora (mean 7.8 \pm 1.3 ), Pocillopora (mean 6.7 \pm 1.0 ), and branching Porites (mean 5.4 \pm 0.9 ) were among three genus with the highest susceptibility values. Fish susceptibility index in Wakatobi showed a downward trend as more distant with Wangi-wangi Island that has the highest susceptibility values. Graham et al. 2011 assigned a species as having a high susceptibility had a score $>0.6$; therefore there're no site values which more than that. Along with climate disturbance drove habitat loss (Hoegh-Guldberg et al. 2007), the other greatest threat to coral reef fishes is fisheries exploitation (Halpern et al. 2008), a small value of vulnerability in Binongko also in the result of the low activity of fisheries, compared to three other islands.

More macroalgae may lead phase shifts from coral assemblages as the direct and indirect impacts of SST anomaly (Hughes et al. 2007), changes from coral to macroalgal dominance symbolize the global degradation of coral reefs and the functions within it, but this can still be overcome by the presence of herbivore fish which will be described further in adaptive capacity part. The adaptive ability of a site to recover depends on several factors, including hard coral cover, coral size distribution, coral richness, fish biomass, herbivore diversity, and herbivore grazing relative to algal production. The lowest hard coral cover was found at Tomia dominated by soft than hard coral reef, and the highest hard coral cover is 
in Wangi-wangi. Coral cover is linked to increased resilience and recovery but most field studies are showing no correlation between coral cover pre or post-disturbance with recovery rates (Cinner et al. 2013) but it is still used in this calculation with consideration of coral cover showing resilience and resistance to exposure. The more varied the size of the coral is expected to assist reefs to recover. The lack of large adult coral colonies may limit spawning stock and indicate environmental stress that has caused partial colony mortality and fragmentation. In this study, Binongko displays a wider variation in size compared to other locations and the island with the lowest variation is Tomia. Coral richness is expected to promote a recovery, the richer, the more easily it is to recover. Kaledupa has the richest genera between all other islands, although the difference is not so significant.

This study observed that fish biomass value is not highly versatile; The highest fish biomass was observed in Tomia and the lowest was in Kaledupa. Fish biomass is the largest contributor to the value of Adaptive Capacity (Cinner et al. 2013). The diversity of fish herbivores in this was obserseved that Binongko as the highest and Kaledupa was the lowest. The diversity of fish herbivores also play an important role in elimina.

An extreme negative IOD event has occurred in 2016; it is the strongest negative IOD since 1980. A lot of coral bleaching in Wakatobi becomes evident that IOD is affecting the ecosystems. During this event, we have demonstrated the ecological vulnerability assessment which may identify trends and possible adaptation opportunities in the face of climate change. In the ecological perspective, this study has shown the island which most vulnerable to the disturbance and may remain the most vulnerable to climate change if there are no precautions act. The results have shown that Binongko is the least vulnerable than the other islands, other words Kaledupa, Wangi-wangi, and Tomia are marginally more vulnerable. The vulnerability of these Wangiwangi, Kaledupa, and Tomia was unique related to the basis of the framers of their vulnerability values. Figure 12 quite explain the uniqueness of each major island.

Figure 12 is an interactive graph which has shown there is a distribution of ecological vulnerability across the different island on Wakatobi, the value of Adaptive Capacity (y-axis) is reversed which result in 2 kinds of classifications. The first classification is the less vulnerable (bottom left of the graph) with a lower value of sensitivity and a higher value of adaptive capacity, while the top right of the graph is classified as more vulnerable with a higher value of sensitivity and lower value of adaptive capacity. The second classification is base on the position of the island whether above or below the diagonal line (arrow) in the graph, the upper left (i.e., above the arrow) are most lacking in recovery potential, and efforts are needed to ensure that recovery potential can be maximized. Similarly, sites below the arrow have relatively high sensitivity.

Binongko, as shown in Figure 12, lay on the bottom left of the graph with the lowest sensitivity and highest adaptive capacity. Elsewhere of the graph Tomia, Kaledupa, and Wangi-wangi located on top right of the graph which indicates a higher value of vulnerability, however Tomia, Wangi-wangi, and Kaledupa have its own characteristics that make it vulnerable, such as Tomia that become vulnerable because lacks of Adaptive Capacity, while Wangi-wangi become vulnerable because of the very high sensitivity value.

We found a considerable range of exposure, sensitivity, and adaptive capacity among the islands studied and discovered vulnerability status of each island. However, the vulnerability data was standardized data, so it's only meaningful when it was compared with the data set. These shortcomings do not make this research bad, for example by knowing which island has the least adaptive capacity (Tomia) and which island has the most bleaching incidents (Wangi-Wangi), we can do a better coral reefs monitoring during the event and then when the event is gone by focusing on the marked islands and sites, in these case Wangi-Wangi and Tomia.

The discussion of vulnerability includes not only the ecological scope but also other factors such as socio-economic (human factors). However, this study is limited only in ecological vulnerability. The same with ecological sensitivity, human also can be sensitive from the same exposure, for example, people who are depending on fishing and what fish they target will be highly affected and dependent on coral reefs. While human in adaptive capacity is the capacity of people to adapt to understand, reduce and recover from impact, and take advantage of new opportunities created by change. To integrate socio-economic and ecological adaptability will require further analysis and data, but at a glance based on facts in the field we have found, there is a trend in which human activity is inversely proportional to the adaptive capacity and affect the vulnerability value. Binongko with the highest adaptation value, in fact, has the lowest human activity, while tomia which are the main tourism destination in Wakatobi has a low adaptability. According to these cases better management will be needed in Tomia, not only related to ecology but also related to human 
activities, so is Wangi-Wangi where the most bleaching incidents are happening. Other study (Minsaris et al. 2019) has suggested that resilience approach to identify prioritizing stations in Wakatobi for management actions is conservation, fishery management and enforcement, bleaching monitoring and supporting recovery, coral reef restoration, tourism structuring, and Land-based sources of pollution reduction.

\section{Conclusion}

The three facets of ecological vulnerability (exposure, sensitivity and recovery potential) were not strongly correlated, indicated that there was no single driver of vulnerability that makes a site particularly vulnerable; rather, the location vulnerability as the result of a combination of adaptive capacity, sensitivity, and exposure. This study compares every major island vulnerability and finds that Wangi-wangi, Kaledupa, and Tomia marginally more vulnerable than Binongko. Those comparisons may lead to better management strategy to deal with a climate anomaly that focused on the more vulnerable island. Type of management can be customized based on the adaptive capacity data, to complement the shortcomings.

\section{Acknowledgements}

We would like to thank to all the institutions that have made this study possible: Center for Coastal and Marine Resources Studies (CCMRS) IPB, UNDP Jakarta Office, Direktorat Adaptasi Perubahan Iklim Direktorat Jenderal Pengendalian Perubahan Iklim Kementerian Lingkungan Hidup dan Kehutanan, Wakatobi National Park.

\section{References}

Adger NA. 2006. Vulnerability. Global Environmental Change 16:268-281.

Berumen ML, Pratchett MS. 2006. Recovery without resilience: persistent disturbance and long-term shifts in the structure of fish and coral communities at Tiahura Reef, Moorea, French Polynesia. Coral Reefs 25:647-653.

Burke L et al. 2011. Reefs at Risk Revisited. Washington DC: World Resources Institute.

Cesar H. 2002. Coral Reefs: Their Functions, Threats and Economic Value. Collected Essays on the Economics of Coral Reefs, Coral Reef Degradation in the Indian Ocean. Sweden: Kalmar.

Cheal et al. 2010. Coral macroalgal phase shifts or reef resilience: links with diversity and functional roles of herbivorous fishes on the Great Barrier Reef. Coral Reefs 29:1005-1015.
Cinner et al. 2013. Social-ecological Vulnerability of Coral Reef Fisheries to Climatic Shocks. Rome: FAO Fisheries and Aquaculture Circular No. 1082.

Effendie MI. 1979. Metode Biologi Perikanan. Bogor: Yayasan Dewi Sri.

English S et al. 1997. Survey Manual for Tropical Marine Resources . 2nd Ed. Townsville: Australian Institute of Marine Science.

Glynn PW. 1993. Coral reef bleaching ecological perspectives. Coral Reefs 12:1-17.

Graham NAJ et al. 2007. Lag effects in the impacts of mass coral bleaching on coral reef fish, fisheries, and ecosystems. Conserv Biol 21:1291-1300.

Graham et al. 2011. Coral reef recovery dynamics in a changing world. Coral Reefs 30:283-294.

Halpern BS et al. 2008. A global map of human impact on marine ecosystems. Science 319:948-952.

Henderson-Seller B, Markland HR. 1987. Decaying Lakes-The Origins and Control of Cultural Eutrophication. New York: Wiley.

Hughes TP et al. 2003. Climate change, human impacts, and the resilience of coral reefs. Science 301:929-933.

Hughes TP et al. 2007. Phase shifts, herbivory, and the resilience of coral reefs to climate change. Curr Biol 17:360-365.

Hughes $S$ et al. 2012. A framework to assess national level vulnerability from the perspective of food security: The case of coral reef fisheries. Environmental Science and Policy 23:95-108.

Hoegh-Guldberg O. 1999. Climate change, coral bleaching and the future of the world's coral reefs. Marine and Freshwater Research 50:839-866.

Hoegh-Guldberg O et al. 2007. Coral reefs under rapid climate change and ocean acidification. Science 318:1737-1742.

Ionescu C et al. 2009. Towards a formal framework of vulnerability to climate change. Environmental Modeling and Assessment 14:1-16.

Ives AR, Carpenter SR. 2007. Stability and diversity of ecosystems. Science 317:58-62.

Lins de Barros MM, Débora de Oliveira P. 2006. Colony sizefrequency distributions among different populations of the scleractinan coral Siderastrea stellata in Southwestern Atlantic: implications for life history patterns. Braz j oceanogr 54:213-223.

Loya Y. 2001. Coral bleaching: the winners and the losers. Ecol Lett 4:122-131.

Madduppa H et al. 2015. Persistent outbreaks of the "black disease" sponge Terpios hoshinota in Indonesian coral reefs. Marine Biodiversity 47:149-151.

Maina J et al. 2011. Global gradients of coral exposure to environmental stresses and implications for local management. PLOS ONE 6:1-14.

Marshall P, Baird A. 2000. Bleaching of corals on the Great Barrier Reef: differential susceptibilities among taxa. Coral Reefs 19:155-163.

McClanahan TR. 1992. Resource utilization, competition and predation: a model and example from coral reef grazers. Ecological Modelling 61:195-215.

McClanahan TR. 1995. A coral reef ecosystem-fisheries modelimpacts of fishing intensity and catch selection on reef structure and processes. Ecological Modelling 80:1-19.

McClanahan T et al. 2002. Ecological states and the resilience of coral reefs. Conservation Ecology 6:18. DOI:10.5751/ ES-00461-060218 
McClanahan TRet al. 2004. Comparing bleaching and mortality responses of hard corals between southern Kenya and the Great Barrier Reef, Australia. Mar Poll Bull 48:327-335.

McClanahan TR et al. 2007a. Western Indian Ocean coral communities: bleaching responses and susceptibility to extinction. Mar Ecol Prog Ser 337:1-13.

McClanahan TR et al. 2007b. Effects of climate and seawater temperature variation on coral bleaching and mortality. Ecological Monographs 77:503-525.

Meesters WH et al. 2001. Colony size-frequency distributions of scleractinian coral populations: spatial and interspecific variation. Mar Ecol Prog Ser 209:43-54.

Minsaris LOA et al. 2019. The potential relative resilience of coral reefs in Wakatobi as a sustainable management foundation. Journal of Coastal Conservation 23:9951004.

Pet-Soede L, Erdmann M. 2004. Rapid Ecological Assessment Wakatobi National Park. Denpasar: WWF Indonesia Marine Program.
Reynolds RW et al. 2002. An improved in situ and satellite SST analysis for climate. J Clim 15:1609-1625.

Saji NH et al. 1999. A dipole mode in the tropical Indian Ocean. Nature 401:360-363.

Siebeck UE et al. 2006. Monitoring coral bleaching using a colour reference card. Coral Reefs 25:453-460.

Smit B, Wandel J. 2006. Adaptation, adaptive capacity and vulnerability. Global Environmental Change 16:282-292.

Sukarno et al. 1983. Terumbu Karang di Indonesia. Jakarta: Lembaga Ilmu Pengetahuan Indonesia.

Turak E. 2003. Coral Reef Surveys During TNC SEACMPA RAP of Wakatobi National Park, Southeast Sulawesi Indonesia (May):2003. Denpasar: The Nature Conservancy.

Wooldridge SA. 2009. Water quality and coral bleaching thresholds: formalising the linkage for the inshore reefs of the Great Barrier Reef. Marine Pollution Bulletin 58:745-751. 